\title{
Transaction B ehavior in Nonmarket Settings: Revisiting Transaction Cost Economics Theory
}

\author{
JungWook Seo* and Seeun Ryu**
}

\begin{abstract}
This study focuses on changes in transaction costs over time in nonmarket settings. Traditional Williamsonian transaction cost economics theory shows little concern with time. However, this study reveals that time is a crucial factor in the fluctuation of transaction costs in nonmarket settings: Transaction costs increase in the initial and middle phases of a transaction. But in the long term, they may increase or decrease and are affected considerably by whether the rules, procedures, and protocols governing the transaction are effective ("green tape") or ineffective ("red tape"). In contrast, traditional transaction cost economics assumes a gradual decrease in transaction costs over time. The passage of time and the "red tape" or "green tape" governing the transaction influence stakeholders' transaction behavior in nonmarket settings.
\end{abstract}

Keywords: transaction costs, green tape, red tape, nonmarket settings, transaction behavior

\section{INTRODUCTION}

Numerous actors and stakeholders are closely intertwined when they carry out transactional behavior such as collaboration and cooperation in nonmarket settings. The concept of network can be transferred to nonmarket settings (Camagni, 1993; Capello, 2000; Chesnais, 1988). A network provides externalities of complementary and vertical integration or from synergy and co-operation" among stakeholders (Capello, 2000, p. 1926). Complementary relationships cause "synergic effects in cooperative activities, achieved through participation in the network" (Capello, 2000, p. 1927). These positive externalities reduce transaction costs. ${ }^{1}$ Sound network gover-

\footnotetext{
* JungWook Seo is a researcher in the Institute of Public Affairs at Yonsei University. E-mail: gomsense@gmail.com.

** Seeun Ryu is a doctoral student in the School of Public Affairs at Arizona State University. E-mail: deepearly38@gmail.com.
}

Manuscript received November 26, 2011; out for review February 6, 2012; review completed March 19, 2012; accepted March 25, 2012.

The Korean Journal of Policy Studies, Vol. 27, No. 1 (2012), pp. 23-40.

(C) 2012 by the GSPA, Seoul National University 
nance positively influences transaction behavior between internal and external stakeholders (Clingermayer, 1997; Prager, 1994). Interconnection or networking among internal and external interested parties is necessary for facilitating decision-making, and it can contribute to reduced transaction costs in nonmarket settings.

This paper attempts to describe the relationship between transactional behavior and transaction costs over time. It describes increases and decreases in transaction costs in the short, medium, and long term. According to Williamson's traditional theory, transaction costs are more likely to be reduced through institutionalizing processes. This study is concerned with the change in transaction costs when stakeholders are involved in a nonmarket setting. It extends the range of transaction costs theory to the nonmarket setting 2 and investigates its changes over time. In nonmarket settings - transactions, collaborations, and cooperation between public institutions, or between public institutions and nonprofit organizations - administrative rules, procedures, and protocols might positively or negatively affect change in transaction costs in the long term. Based on this assumption, this paper seeks to answer the following core questions:

1. Do stakeholders' transaction behaviors affect the change in transaction costs in nonmarket settings?

2. Over time, are there changes in transaction costs and transaction behaviors?

3. Which factors explain these changes?

Focusing on these questions, this paper employs an adjusted transaction costs graph (Williamson, 1989), which applies to the economics concepts of fixed costs and variable costs.

\section{LITERATURE REVIEW AND PROPOSITIONS}

\section{Conceptualizing the Nonmarket Setting}

Williamson's traditional transaction cost economics (TCE) theory assumes a gradual decrease in transaction costs. Many studies have verified this assumption in market

1. Transaction costs are defined as "the costs of negotiating, enacting, and enforcing the provisions of a contact or informal agreement and an external supplier of a service" (Clingermayer, 1997, p. 231).

2. Initially, Williamson was concerned with market settings, and thus, his transaction costs theory was developed through case studies of private firms (Williamson, 1975, 1981, 1985). 
settings; their main research targets have been private corporations and companies. This study suggests that transaction costs and transactions in nonmarket settings can be different from those in market settings.

Profit and productivity are not the guiding principles when institutions carry out transaction behaviors in nonmarket settings. Transactions in nonmarket settings are different from those in market settings in that the former do not consider direct distribution of profit to stakeholders. Various transaction behaviors, including collaboration, conflict, and cooperation among stakeholders, are related to the realization of the public interest and social values or missions. In general, transactional behavior in nonmarket settings is likely to occur (1) between public institutions and other public institutions and (2) between public institutions and nonprofit organizations.

Administrative rules, regulations, protocols, and procedures can heavily influence transactional behavior because public organizations play a crucial role in nonmarket settings. On the other hand, reducing costs based on efficiency is a main purpose of transactional behavior in market settings. In general, diverse collaborations, transactions, and cooperation in nonmarket settings are concerned with political legitimization more than with efficiency.

\section{Transactions in Nonmarket Settings}

Transactions or transaction behaviors are now an important issue in the field of public administration. The World Bank (1991) defines governance as "the exercise of political authority and the use of institutional resources to manage society's problems and affairs." S@ ${ }^{\mathrm{TM}}$ rensen and Torfing (2007) define governance networks as follows (p. 9):

1. a relatively stable horizontal articulation of interdependent, but operationally autonomous actors

2. who interact through negotiations

3. which take place within a regulative, normative, cognitive and imaginary framework

4. that is self-regulating within limits set by external agencies, and

5. which contributes to the production of public purpose

Transactions in nonmarket settings involve interactions between diverse actors who are not viewed "as atomized and isolated, but as mutually interlinked" (Adam \& Kriesi, 2007, p. 146). In the nonmarket setting, interactions increase since stakeholders require each other's resources to attain their interests (Aldrich, 1979). There is selforganized coordination among stakeholders, who negotiate and solve problems without 
government direction (Rhodes, 1997). How actors behave and interact in the nonmarket setting determines the success of outcomes and alternation.

Increasing interactions, including information exchanges and regular communications, establish a stable pattern of relationships between actors (Kickert, Klijin, \& Koppenjan, 1997). In nonmarket settings, network management helps to initiate, guide, facilitate, and stabilize interaction processes (Friend, Power, \& Yewlett, 1974). Network management promotes "the negotiation process through conflict mediation, process planning, and diplomacy" (Rhodes, 1997, p. 24). Dean (1999) argues that network management builds partnerships, hearings, negotiations, user boards, free choice, and participation incentives. It contributes to building a set of norms, standards, benchmarks, procedures, protocols, and control mechanisms. This study is concerned with relationships among various stakeholders in nonmarket settings.

\section{Transaction Costs}

Transaction cost economics (TCE) theory draws attention to efficiency in transactions among stakeholders. ${ }^{3}$ There are many definitions of transaction cost. Demsetz (1968) defines it narrowly: "transaction cost may be defined as the cost of exchanging ownership titles" (p. 35). Coase (1960) refers to "the cost of using the price mechanism" and "the costs of carrying out market transactions" between firms or between individuals and firms "to inform people that one wished to deal and on what terms, to conduct negotiations leading up to a bargain, to draw up the contract, to undertake the inspection needed to make sure that the terms of the contract are being observed and so on" (p. 7). Wallis and North (1986) define it as "all costs borne by the consumer that are not transferred to the seller of the good" (p. 98). Investment costs in financial markets, such as brokerage fees and ask-bid spreads, are generally regarded as transaction costs in financial economics (Bhardwaj \& Brooks, 1992; Demsetz, 1968; Stoll and Shaley, 1983; Wang, 2003). Dyer (1997) presents four types of transaction costs (p. 536): search costs, contracting costs, monitoring costs, and enforcement costs. McCann, Colby, Easter, Kasterine, and Kuperan (2005) extend the range of transaction costs to the public policy area. Transaction costs include (McCann et al., 2005, p. 533):

1. research, information gathering, and analysis associated with defining the problem

2. enactment of enabling legislation, the cost of changing laws

3. In contrast, many traditional economic models and theories stress internal efficiency in producing goods and services. 
3. design and implementation of the policy

4. support and administration of the ongoing program

5. contracting costs, including additional information costs, bargaining costs, decision costs, tax/subsidy scheme, or private contract, as well as the development of monitoring technologies

6. prosecution/inducement/conflict resolution costs incurred if lack of compliance is found

There is a wide spectrum of ways to reify or operationalize transaction costs, including the following:

1. a direct measurement of transaction costs-resources used for locating stakeholders and implementing transaction behaviors (Benham \& Benham, 1998; Colby, 1990; de Soto, 1989)

2. the difference between the price paid by the buyer and that received by the seller (Bhardwaj \& Brooks, 1992; Demsetz, 1968; Stoll \& Shaley, 1983; Wang, 2003, p. 2)

3. secondary transaction costs - that is, the cost for negotiation and enforcement (Wang, 2003; Williamson, 1985, 1989, 1991)

This study defines transaction costs broadly as all the resources that are required for transaction behavior among internal and external stakeholders. Transaction costs include tangible and intangible resources — such as knowledge, information, money, and human resources - that are related to transaction behavior. In addition, they include resources for carrying out indirect transactions such as negotiation, monitoring, administrative support, and enforcement.

The Williamsonian TCE graph (figure 1) determines the governance structure between an internal organization (firm) and market when researchers know the level of asset specificity for a transaction, the frequency of interactions among stakeholders, and the degree of uncertainty (Chiles \& McMackin, 1996; Williamson, 1975, 1985). $\Delta \mathrm{G}$ stands for the differences between "the bureaucratic costs of internal governance$\mathrm{B}(\mathrm{k})$ and the corresponding governance costs of markets- $\mathrm{M}(\mathrm{k})$, where $\mathrm{k}$ is an index of asset specificity" (Williamson, 1989, p. 151). If ?G is more than zero, an internal organization would be preferred; if $\Delta \mathrm{G}$ is less than zero, the market type of governance structure is favored.

Williamson's traditional curve mainly focuses on predicting the governance structure that adopts the transaction with the related parties and minimizes its costs. His approach shows little concern about the differences in transaction costs in different time horizons - short- and long-term transactions between internal and external stake- 
Figure 1. Traditional Curve of Williamson's Transaction Costs

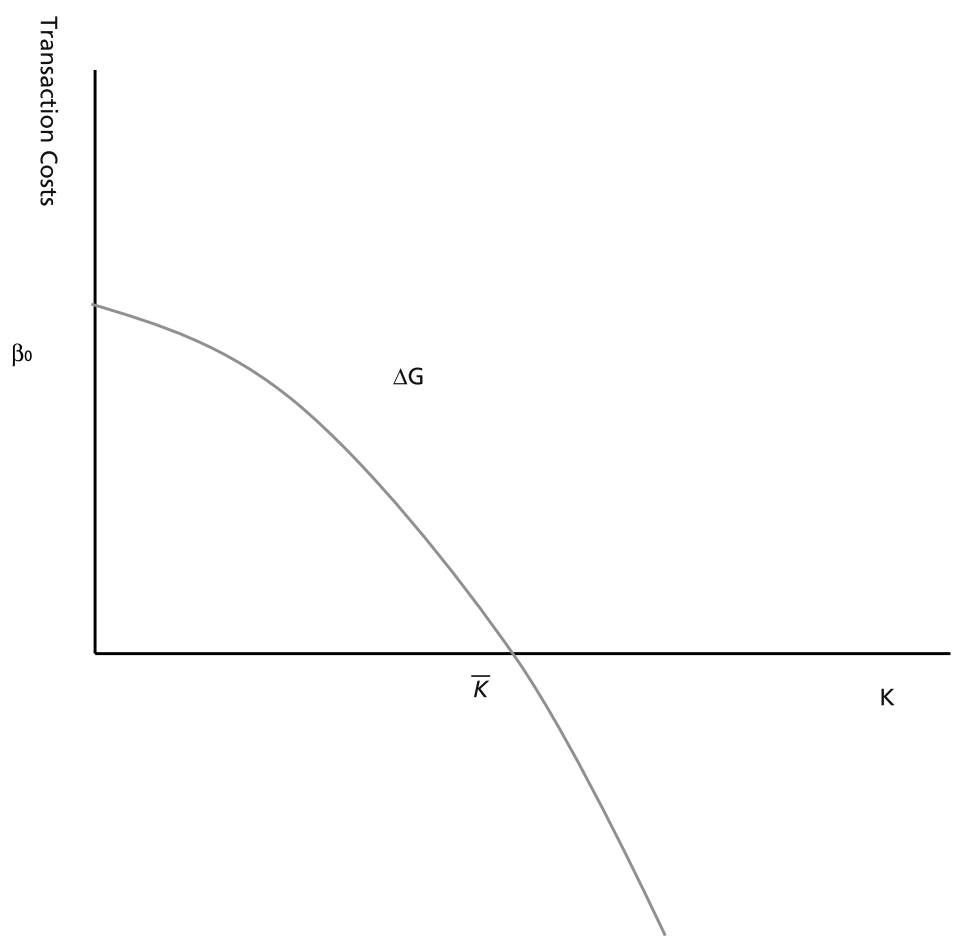

Source: Williamson, 1989, p. 159.

holders (Dyer, 1997). A few studies have focused on transaction costs and transaction behavior in nonmarket settings (e.g., de Soto, 1989; Kang, 2005; Kim, 2005; Kim \& Song, 2002). For example, de Soto (1989) presents and measures nonmarket transaction costs. He operationalizes transaction costs as waiting time, bribes for public servants, and resources wasted by organizational red tape during transaction behavior. However, these studies, too, have paid little attention to the effect of time on changes in transaction costs.

This study explores the change in transaction costs over time, and presents the following proposition:

Proposition 1. Transaction costs in nonmarket settings are likely to fluctuate over different time horizons. 


\section{Transaction Costs, Organizational Rules, and Time}

Rules, regulations, processes, procedures, and protocols considerably influence organizational structure, behavior, and performance. Organizational rules, regulations, and procedures affect the efficiency and effectiveness of transaction behavior. Traditionally, many theorists and experts also have paid attention to a negative aspect of organizational rules, procedures, and regulations - red tape or ineffective rules (DeHart-Davis, 2009a, 2009 b). Red tape has been considered an obstacle to organizational efficiency and effectiveness in both the public and private domain. Bozeman (2000) argues that red tape has a negative effect on public organizations, since it wastes resources and detracts from the achievement of legitimate objectives. Common characteristics of red tape include the following:

1. high formalization and constraint (Hall, 1968)

2. excessive or unnecessary paperwork (Bennett \& Johnson, 1979)

3. unnecessary rules, procedures, and regulations

4. inefficiency (Bozeman, 1993)

5. unjustifiable delays (Bozeman, Reed, \& Scott, 1992)

However, some scholars point out that there are also beneficial aspects of rules, regulations, and procedures in organizational behavior and performance (Benveniste, 1987; Bozeman, 1993, 2000; DeHart-Davis, 2009a, 2009b; Goodsell, 2000). Organizational rules sometimes confer benefits in the form of procedural safeguards that guarantee accountability, predictability, and fairness in administrative and policy decisions (Bozeman, 1993, 2000). Landau (1969) says that duplication and overlapping of procedures or tasks can provide important benefits. Employees in public and private organizations are likely to face uncertainty or ambiguity without appropriate rules, procedures, and regulations. Effective rules, or "green tape,"4 are regarded as a normal part of bureaucracy. DeHart-Davis (2009b) argues that bureaucratic green tape could boost public employees' rule abidance as stakeholders.

Some scholars focus on the relationship between ineffective bureaucracy (red tape) and changes in the costs of transactional behavior (de Soto, 1989; Falconer \& Saunders, 2002). They state that cutting red tape has a positive effect on reducing transaction costs in both market and nonmarket settings. However, scholars pay little attention to changes in transaction costs from green tape or effective rules and normal bureaucratic behavior. The negative effects of red tape or ineffective rules are closely associated

4. These are labeled "green tape to contrast with red tape" (DeHart-Davis, 2009a, p. 362). 
with inefficiency, excessive regulations, and frustrations in a bureaucracy; the benefits of effective rules or green tape mainly come from redundancy, accountability, and rule abidance. In the governance set-up process, the initial phase of a transaction, rules, protocols, and procedures influence the change in transaction costs. Such a rule-setting process results in an increase in transaction costs. The application of effective or ineffective rules considerably affects transaction costs or transaction behavior in the long term. This study uses the following proposition:

Proposition 2. Rule maturity (the perception of rules over time) is likely to influence the change in transaction costs.

Once established, rules, procedures, and protocols supporting transactions are difficult to change even though they may lead to inefficiency in transaction processes (Burger, 1981; Skocpol et al., 1985). Such rules are characterized by path dependence, and can affect ongoing transactions. This study is concerned with the relationship between good and bad organizational rules (red and green tape) and the change in transaction costs in nonmarket settings. Organizational members' perceptions of organizational rules, procedures, and protocols is a critical standard for determining whether an organization has red tape or not. The perception is formed "by humans in repetitive situations organized by rules, norms, and strategies" (Ostrom, 2007, p. 23). It has been mutually constructed in parties' minds over time rather than right after the forming of rules, procedures, and protocols. Thus it is possible to consider the effect of red tape or green tape on transaction costs in the long term. This study makes the following propositions:

Proposition 3. Red tape or ineffective rules are likely to negatively influence transactional behavior and transaction costs in the long term.

Proposition 4. Green tape or effective rules are more likely to reduce transaction costs in the long term.

\section{TRANSACTION COSTS OVER TIME}

Bounded rational individuals experience conflict, mutuality, and order (Commons, 1932). Even though many researchers have discussed transaction costs in the creation of organizations (Moe, 1984; Williamson, 1979, 1999), transaction costs theory is also applicable to transaction behavior, including collaboration, conflict, and coordination, in nonmarket settings. Based on the assumptions of TCE, the parties in the transaction 
behavior are economic groups (actors) who "have the capacity to look ahead, recognize potential hazards, and factor these into the transactions" (Williamson, 1999, p. 311). Bounded rational actors could calculate intuitively and reasonably the difference between "benefits/costs of autonomy and cooperation" (Williamson, 1999, p. 312) and decide whether to remain independent or to cooperate with each other. Stakeholders and parties such as citizens, nonprofit organizations, governments, business, and councils are involved in the transaction process in nonmarket settings.

\section{Transaction Costs in the Initial and Middle Stages}

In the nonmarket setting, initial interconnections or transactions between stakeholders are increasing since stakeholders have to set up the institution including its norms, procedures, rules, protocols, and regulations (Egdell, 1998; McCann et al., 2005; Williamson, 1979). Dyer (1997) calls these costs "governance set-up costs" (p. 537). Stakeholders set "humanly devised constraints" that organize interactions and transactions (North, 1992, p.?4). They create "formal rules (statute law, common law, regulations), informal constraints (conventions, norms of behavior, and self-imposed rules of behavior), and the enforcement characteristics of both" (North, 1992, p. 4).

Regardless of the form of transaction, most transactional behavior among stakeholders has direct and secondary costs. Transaction costs are involved in building network structures, including the costs of identifying and evaluating parties and negotiating and writing contracts. Fang and colleagues (2005) demonstrate that about 65 percent of transaction costs are incurred before any transaction takes place. However, the costs do not increase linearly in proportion to the degree of a transaction. The slope of a transaction costs curve is likely to be gentle from initial phase to middle phase, as shown in figure 2 .

The transaction costs, including time and money, involved in becoming personally acquainted and creating collaboration and cooperation with stakeholders, increase before transactions are regularized and stabilized. Transactions including communication and frequent exchange of information between actors eventually become regularized and stable. The actors coordinate their mutual interests as interactions increase (Adam \& Kriesi, 2007). Institutionalized rules and procedures help people know how to interact and work together. Thus even added transactions between multiple actors at multiple levels do not cost at the same ratio. The marginal cost for transactions gradually diminishes after rules and procedures are institutionalized (see figure 2).

There are two kinds of transaction costs: fixed and variable over time. In the processes of collaboration, conflict, and coordination in nonmarket settings, fixed transaction costs are for supporting and managing transaction behaviors (McCann \& 
Figure 2. Transaction Costs in the Initial and Middle Phases

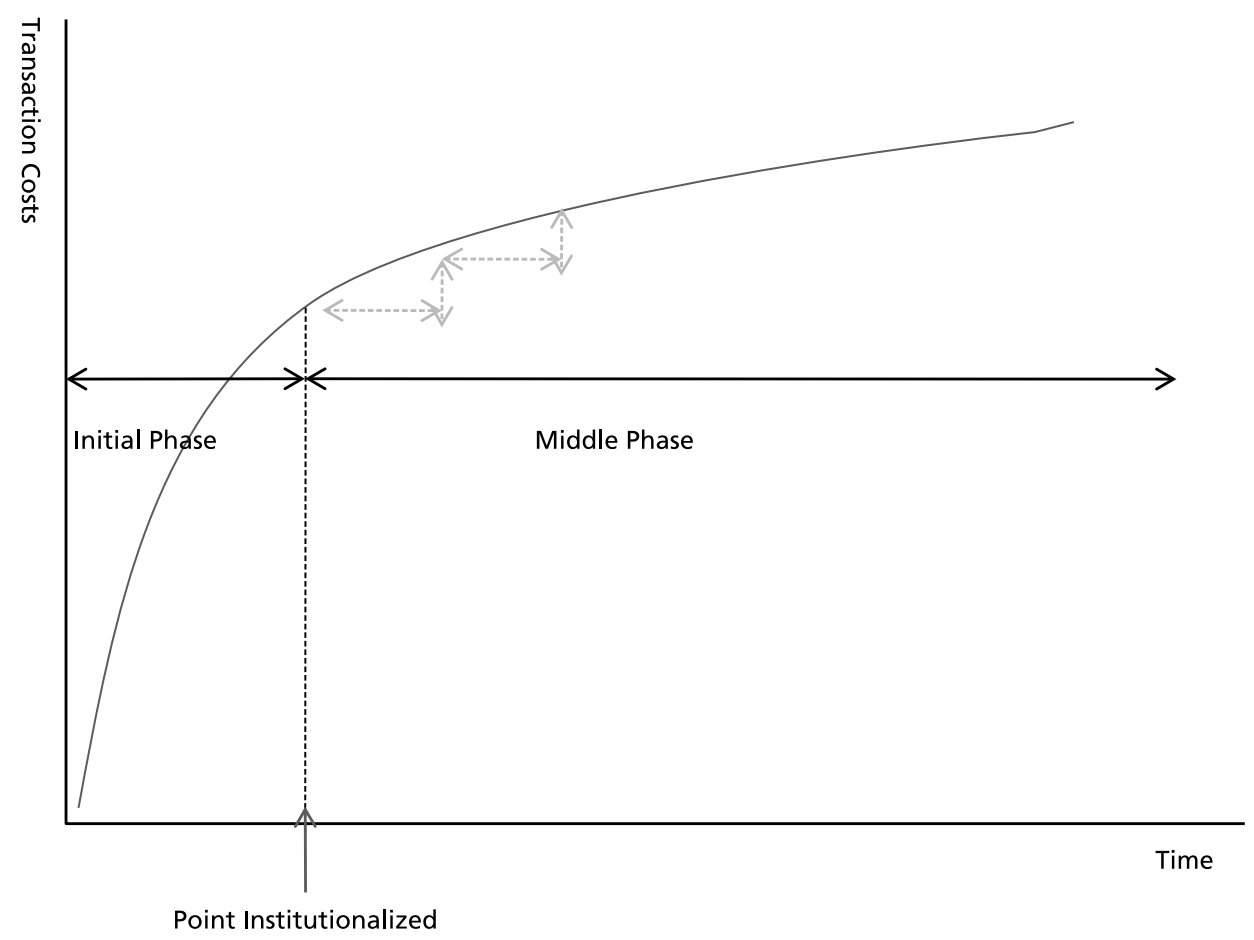

Easter, 1999, 2000). In the initial and middle stages, fixed transaction costs hardly change, as presented in figure 3. Variable transaction costs are associated with the changes in proportion to the exchange in the nonmarket setting over time (Falconer \& Saunders, 2002). In general, variable transaction costs for smoothing stakeholders' interactions increase during the setting process (initial stage). The setting costs include the efforts to establish rules, protocols, regulations, and procedures to manage and support transactional behavior. Variable transaction costs are affected by situational factors such as development of monitoring and abatement technologies, changes in political environment, and economic fortunes. Situational factors can lead to a decrease in transaction costs (McCann, 2005) as time passes (see figure 3). 
Figure 3. Fixed and Variable Transaction Costs

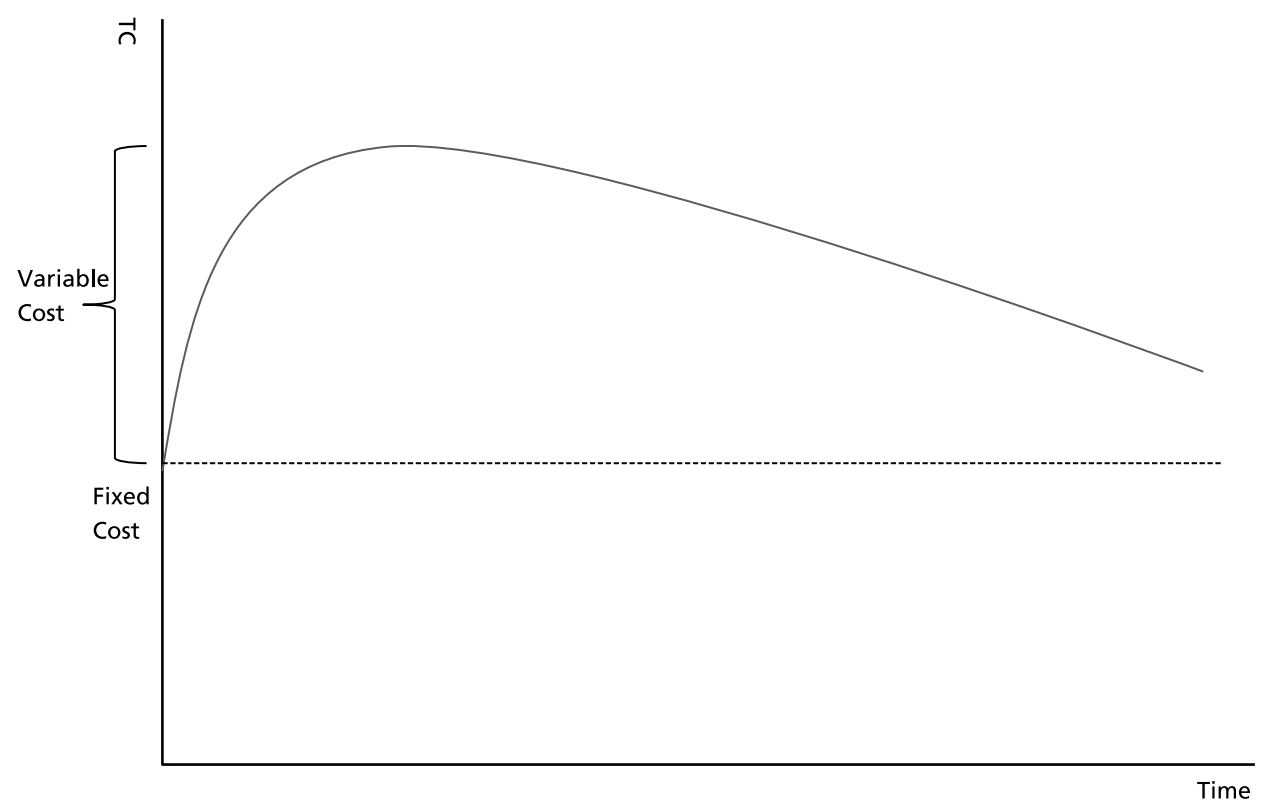

\section{Transaction Costs in the Long Term}

The change in transaction costs in the long term is different from the change during the initial and middle stages. Nonmarket transaction costs can either decrease or increase in the long term, while they are more likely to increase in the initial stage of governance set-up. This section presents two scenarios for change in transaction costs: decrease and increase.

This study assumes that effective and ineffective rules for managing and supporting relations between parties significantly affect transaction costs in the long term. In nonmarket settings, transaction costs increase when parties consider rules to be burdensome or unnecessary, and decrease when parties consider rules to be helpful and beneficial to their transactional behavior.

\section{Decrease in Transaction Costs}

Institutionalized networking or interaction processes are likely to accompany costs - that is, these costs are regarded as fixed in the long term. Stakeholders can reduce the trials and errors of the contracting process when formalized and well-written protocols, rules, or procedures are applied to the interactions in nonmarket settings. 
The application of well-written rules grants strong legitimacy to transaction behaviors between stakeholders (Ford \& Johnson, 1998). The legitimacy of the application of formalized and well-written rules can improve rule compliance and cooperation among stakeholders (Barnard, 1938; DeHart-Davis, 2009a, 2009b).

"Optimally controlling rules or green tape" (DeHart-Davis, 2009a, 2009b) provide stakeholders with flexibility in interactions and interrelations. Good rules impose "what [is] perceived as just the right amount of control" (DeHart-Davis, 2009a, p. 368). It is not easy for stakeholders to carry out appropriate transactional behavior for reaching an agreement when an organizational structure is very bureaucratic - that is, when an organization has complicated and fixed organizational rules, procedures, and protocols for interactions and networking with outside stakeholders. Flexible rules, protocols, or procedures would encourage stakeholders to reach an agreement for cooperation, because flexibility allows stakeholders to consider various alternatives during their transactional behaviors.

Stakeholders' understanding of rules, procedures, and protocols for administering transactions makes it easy to reach a consensus. Rules are likely to be red tape unless stakeholders do not understand their purpose (Bozeman, 2000; DeHart-Davis, 2009b). Well-understood rules can reduce conflicts among stakeholders in the long term.

Consistent and fair application of rules for networking and transactions can promote the participation of outside stakeholders including individuals, corporations, and nonprofit organizations over time. Fair rules, procedures, and protocols are thought to reduce uncertainty in the interactions between parties (DeCremer \& Tyler, 2005). Decrease in uncertainty and increase in participation in transactions are likely to induce sound competition among outside stakeholders. Such competition will contribute to parties reducing costs in the long term. Figure 4 reveals the decrease in transaction costs under the application of effective rules (green tape) over time. ${ }^{5}$

5. In long-term situations, it is not necessary to consider changes in fixed costs and governance set-up costs. These costs naturally decrease as time goes by, and their burden might be distributed over a long time frame. 
Figure 4. Transaction Costs and Application of Effective Rules

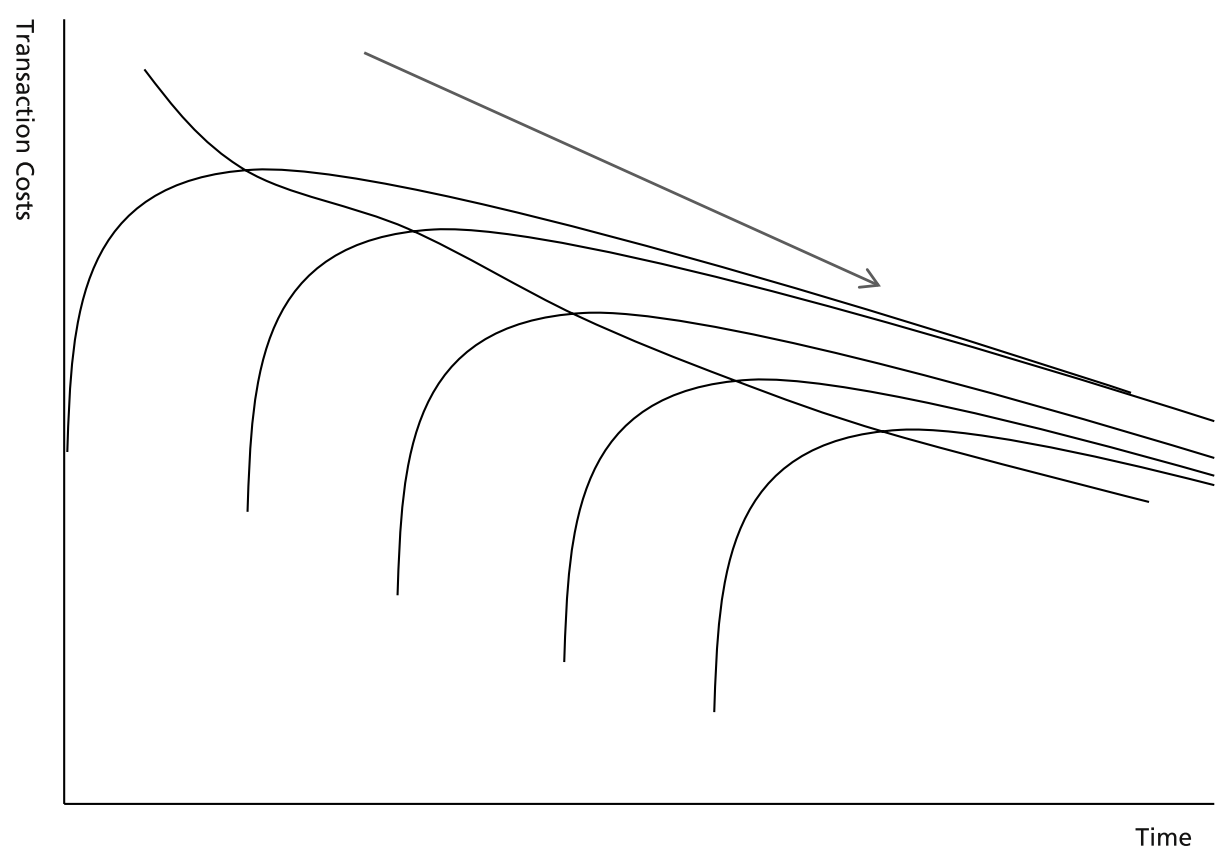

\section{Increase in Transaction Costs}

This study suggests that rule (in)effectiveness has positive or negative effects on transaction costs and stakeholders' transaction behavior. ${ }^{6}$ This section discusses the relationship, over the long term, between the application of ineffective rules, procedures, and protocols (red tape) and changes in transaction costs in nonmarket settings.

Ineffective rules, procedures, and protocols (red tape) are associated with lack of trust between stakeholders (Gouldner, 1952). This lack of trust has negative effects on transactional behavior over time. Ineffective rules are likely to decrease the effectiveness of transactional behavior in nonmarket settings in that they hinder trust building between stakeholders. According to Dyer (1997), "information sharing, commitment to future interaction (networking), and self-enforcing safeguards (norms, rules, protocols) to govern the relationship" (550-551) have a positive causal relationship with trust-building in the administrative process or transactional behavior. Increase in trustworthiness within the exchange behavior contributes to reducing transaction costs (Dyer, 1997;

6. Studies have pointed out that "self-interest seeking with guile" is a major reason that costs increase in transactional behavior (Dyer, 1997; Williamson, 1985). 
Figure 5. Ineffective Rules and Transaction Costs over the Long Term

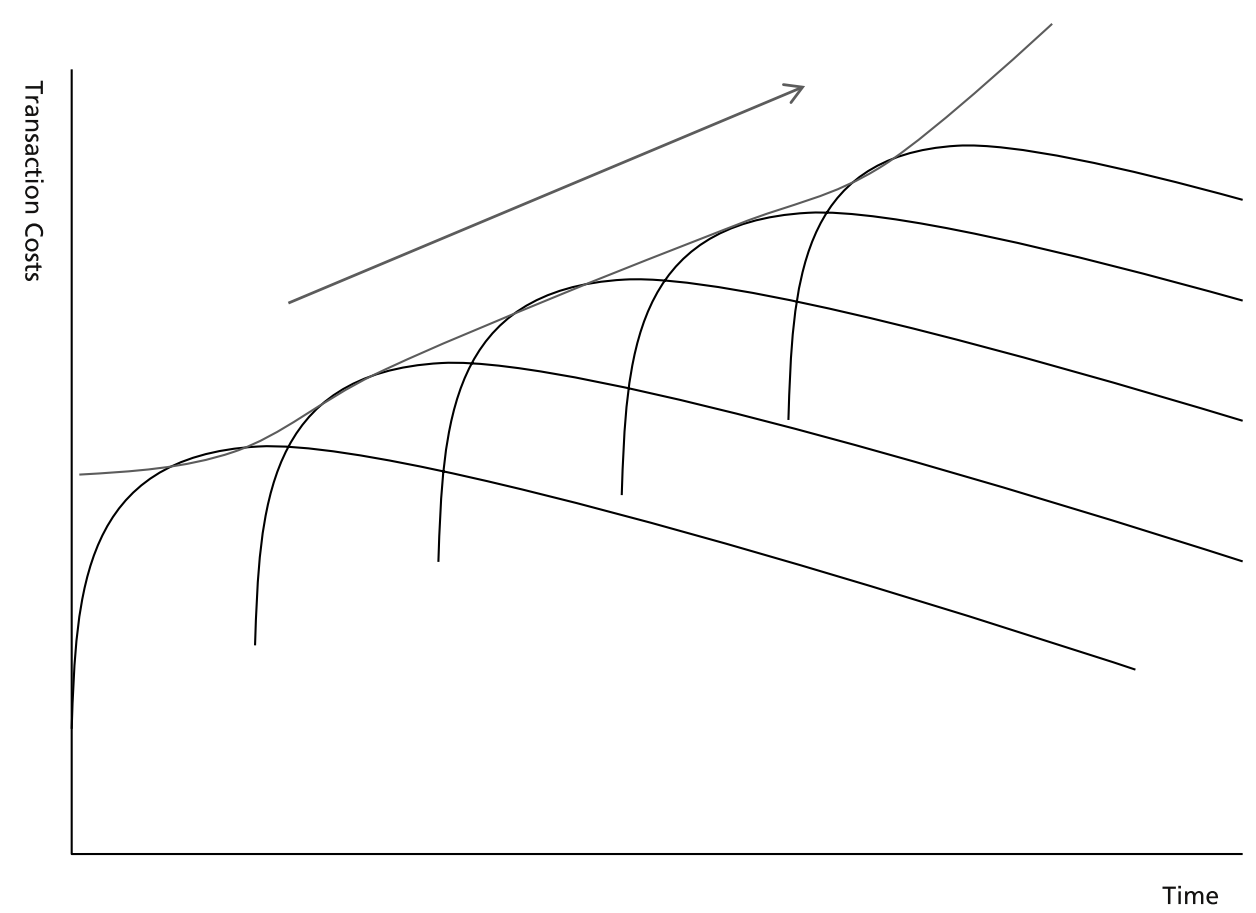

Ulrich \& Barney, 1984). De Soto (1989) asserts that decrease in ineffective organizational rules (cutting red tape) in transactional behavior reduces transaction costs in the nonmarket setting. Ineffective rules are likely to increase transaction costs among internal and external stakeholders. Figure 5 shows the change in transaction costs from the application of ineffective rules over the long term.

\section{CONCLUSION}

This study presents propositions about the relationship between time and transaction costs in transaction behavior in nonmarket settings. It addresses the change in transaction costs over time-during the initial, mid-term, and long-term periods. In the early to middle stages, core participants in nonmarket settings, including government and related stakeholders, seek to form network governance to promote transaction behavior (such as collaboration and cooperation). Parties are building relationships, gathering information, and forming various safeguards to facilitate the processes of transactional behavior. These activities accompany an increase in fixed and variable 
transaction costs. The increase occurs mainly in the initial stage of transactions. Like sunk costs, fixed transaction costs hardly change over time; in contrast, variable transaction costs are likely to decrease from the initial stage to the middle stage.

This study addresses situations in which transaction costs decrease or increase in the long term. It suggests that effective or ineffective rules (red tape or green tape) for supporting and managing transactional behavior between stakeholders can affect this change in transaction costs. Rules are thought to be effective if they are (1) formalized and well written, (2) flexible (optimally controlling), (3) fair and consistent, and (4) understandable (DeHart-Davis, 2009a, 2009b). Effective rules are expected to reduce transaction costs in the long term, while ineffective rules can increase costs. Rules are regarded as ineffective when stakeholders perceive them as unnecessary or burdensome. Such rules hinder trust building when stakeholders engage in transactional behavior.

This study reveals the importance of time on TCE. Many studies in public administration and policy hardly consider the relationship between time and changes in transaction costs. Theoretical studies mainly focus on how to conceptualize transaction behavior and transaction costs and how to measure transaction costs. Many empirical studies based on traditional TCE theory have emphasized measuring transaction costs at a given time.

Experts in public administration and policy have to consider nonmarket transaction costs when they study transaction costs and transaction behavior in the public and nonprofit sectors. This study expands de Soto's (1989) concept of nonmarket transaction costs to nonmarket settings. Hernando de Soto (1989) the importance of resources spent on "waiting, getting permits to do business, cutting through red tape, and bribing officials" (de Soto, 1989; Wang, 2003, p. 6) during transaction behavior. This study suggests that such nonmarket transaction costs are likely to occur in nonmarket settingstransactions between different public institutions or between public institutions and nonprofit organizations - because it is difficult for public institutions to ignore political legitimization in their transactional behavior.

This is a preliminary study that examines theoretical assumptions. Additional research is needed to examine empirical cases to test the propositions presented here, develop quantifiable measures for more precise prediction of the change in transaction costs, and develop appropriate tools for reifying the power of network governance, collaborations, and cooperation between government officials and outside stakeholders in transactional behavior in nonmarket settings. 


\section{REFERENCES}

Adam, S., \& Kriesi, H. 2007. The network approach. In P. Sabatier (ed.), Theories of the policy process. Boulder, CO: Westview Press.

Aldrich, H. E. 1979. Organizations and environments. Englewood Cliffs, NJ: PrenticeHall.

Barnard, C. I. 1938. The functions of the executive. Cambridge, MA: Harvard University Press.

Benham, A., \& Benham, L. 1998. Measuring the costs of exchange. Manuscript, Washington University in St. Louis.

Bennett, J. R., \& Johnson, M. H. 1979. Paperwork and bureaucracy. Economic Inquiry, 17: 435-451.

Benveniste, G. 1987. Professionalizing the organization: Reducing bureaucracy to enhance effectiveness. San Francisco: Jossey-Bass.

Bhardwaj, R., \& Brooks, L. 1992. The January anomaly: Effects of low share price, transaction costs, and the bid-ask bias. Journal of Finance, 47: 553-574.

Bozeman, B. 1993. A theory of government "red tape." Journal of Public Administration Research and Theory, 3(3): 273-303. .2000. Bureaucracy and red tape. Englewood Cliffs, NJ: Prentice-Hall.

Bozeman, B., Reed, P., \& Scott, P. 1992. Bureaucratic red tape and formalization: Untangling the conceptual knot. Paper presented at the Annual Research Conference of the Association for Public Policy Analysis and Management.

Camagni, R. 1993. Interfirm industrial networks: The costs and benefits of co-operative behavior. Journal of Industry Studies, 1: 1-15.

Capello, R. 2000. The city network paradigm: Measuring urban network externalities. Urban Studies, 37(11): 1925-1945.

Chesnais, F. 1988. Technical co-operation agreements among firms. STI Review, 4.

Chiles, T. H., \& McMackin, J. F. 1996. Integrating variable risk preferences, trust, and transaction cost economics. Academy of Management Review, 21(1): 73-99.

Clingermayer, J. C. 1997. Leadership turnover, transaction costs, and external city service delivery. Public Administration Review, 57(3): 231-239.

Coase, R. H. 1993. The nature of the firm (1937). In O. Williamson \& S. G. Winters (eds.), The nature of the firm: Origins, evolution and development. New York: Oxford University Press.

Colby, B. 1990. Transaction costs and efficiency in western water allocation. American Journal of Agricultural Economics, 72: 1184-1192.

Commons, J. R. 1932. Institutional economics: Its place in political economy. New York: Macmillan. 
Dean, M. 1999. Governmentality: Power and rule in modern society. London: Sage.

DeCremer, D., \& Tyler, T. R. 2005. Managing group behavior: The interplay between procedural justice, sense of self, and cooperation. Advances in Experimental Social Psychology, 37: 151-218.

DeHart-Davis, L. 2009a. Green tape: A theory of effective organization rules. Journal of Public Administration Research and Theory, 19(2): 361-384.

. 2009b. Green tape and public employee rule abidance: Why organizational rule attributes matter. Public Administration Review, 69(5): 901-910.

Demsetz, H. 1968. The cost of transacting. Quarterly Journal of Economics, 82: 33-53.

de Soto, H. 1989. The other path: The economic answer to terrorism. New York: Harper \& Row.

Dyer, J. H. 1997. Effective interfirm collaboration: How firms minimize transaction costs and maximize transaction value. Strategic Management Journal, 18(7): 535-556.

Egdell, J. 1998. A transaction costs approach to the development of agri-environmental policy, using the example of Scotland. Paper presented at the Annual Conference of the Agricultural Economics Society, Reading, England.

Falconer. K., \& Saunders, C. 2002. Transaction costs for SSSIs and policy design. Land Use Policy 19(2): 157-166.

Ford, R., \& Johnson, C. 1998. The perception of power: Dependence and legitimacy in conflict. Social Psychology Quarterly, 61(1): 16-32.

Friend, J. K., Power, J. M., \& Yewlett, C. J. L. 1974. Public planning: The inter-corporate dimension. London: Tavistock.

Goodsell, C. T. 2000. Red tape and a theory of bureaucratic rules. Public Administration Review, 60(4): 373-375.

Gouldner, A. 1952. Red tape as a social problem. In R. Merton, A. Gray, B. Hockey, \& H. Selvin (eds.), Reader in bureaucracy. Glencoe, IL: Free Press.

Hall, R. 1968. Professionalism and bureaucratization. American Sociological Review, 33: 92-104.

Kang, Y. 2005. An analysis on the causes and solutions of non-cooperations and conflicts evolved from the use of the commons between local governments. Korean Public Administration Review, 39(2): 263-285.

Kickert, W. J. M., Klijin, E., \& Koppenjan, J. F. M. 1997. A management perspective on policy networks. In W. J. M. Kickert, E. Kilijin, \& J. F. M. Koppenjan (eds.), Managing complex networks: Strategies for the public sector. London: Sage.

Kim, J. 2005. A comparative analysis of models of contracting: Focused on contracting our garbage collection and welfare facility operation services. Korean Public Administration Review, 39(3): 205-228. 
Kim, Y. M., \& Song, H. J. 2002. Does transaction cost theory explain information systems outsourcing in the U.S. government?: An empirical test. Korean Journal of Policy Studies, 16(1): 51-64.

Landau, M. 1969. Redundancy, rationality, and the problem of duplication and overlap. Public Administration Review, 29: 346-358.

McCann, L., Colby, B., Easter, K. W., Kasterine, A., \& Kuperan, K. V. 2005. Transaction cost measurement for evaluating environmental policies. Ecological Economics, 52: $527-542$.

Moe, T. (1984). The politics of structural choice: Toward a theory of public bureaucracy. In O. E. Williamson (ed.), Organization theory (pp. 116-153). New York: Oxford University Press.

North, D. 1992. Institutions and economic theory. The American Economist, 36(1): 3-6.

Ostrom, E. 2007. Institutional rational choice: An assessment of the institutional analysis and development framework. In P. A. Sabatier (ed.), Theories of the policy process. Boulder, CO: Westview Press.

Rhodes, R. A. W. 1997. Understanding governance: Policy networks, governance, reflexivity and accountability. Buckingham, UK: Open University Press.

Sørensen, E., and Torfing, J. (eds.). 2007. Theories of democratic network governance. London: Palgrave Macmillan.

Stoll, H., \& Shaley, R. 1983. Transaction costs and the small firm effect. Journal of Financial Economics, 12: 57-79.

Ulrich, D. O., \& Barney, J. B. 1984. Perspective in organizations: Resource dependence, efficiency, and population. Academy of Management Review, 9(3): 471-481.

Wallis, J. J., \& North, D. C. 1986. Measuring the transaction sector in the American economy, 1870-1970. In S. L. Engerman \& R. E. Gallman (eds.), Long-term factors in American economic growth. Chicago: University of Chicago Press.

Wang, N. 2003. Measuring transaction costs: An incomplete survey (Working Paper 2, Ronald Coase Institute). St. Louis, MO: Ronald Coase Institute.

Williamson, O. E. 1975. Markets and hierarchy: Analysis and antitrust implications. New York: Free Press.

1979. Transaction cost economics: The governance of contractual relations. Journal of Law and Economics, 22(2): 233-261.

. 1981. The economics of organization: The transaction cost approach. American Journal of Sociology, 87(3): 548-577. 1985. The economic institutions of capitalism. New York: Free Press. 1999. Public and private bureaucracies: A transaction cost economics perspective. Journal of Law Economics and Organization, 15(1): 306-342. 